\title{
Judgment heuristics and recognition memory: Prime identification and target-processing fluency
}

\author{
PHILIP A. HIGHAM \\ University of Northern British Columbia, Prince George, British Columbia, Canada \\ and \\ JOHN R. VOKEY \\ University of Lethbridge, Lethbridge, Alberta, Canada
}

\begin{abstract}
In three experiments, the effect of identification of a briefly presented word (prime) on a subsequent recognition response to that word (target) was investigated. Theories of current processing fluency (e.g., Jacoby \& Whitehouse, 1989) suggest that prime identification should reduce P(old) relative to prime misidentification because awareness of the prime provides a source to which to attribute target fluency, rendering attributions to prior presentation less likely. However, counter to these predictions, Experiment 1 demonstrated that prime identification increased $\mathrm{P}$ (old) relative to misidentified primes. It is hypothesized that this reversed effect was due to participants' using a heuristic that related prime identification success to prior presentation but was not based on current processing fluency. In Experiment 2, participants were induced to avoid using this heuristic by making an alternate source for prime identification success (display duration) highly available. Under these circumstances, prime identification reduced $P($ old ) relative to prime misidentification, suggesting that participants now relied on current processing fluency rather than on prime identification success. Experiment 3 replicated the results of Experiments 1 and 2, but with fixed rather than variable prime displays.
\end{abstract}

Dual-process models of recognition memory assume that there are two mechanisms underlying judgments of prior occurrence (see Mandler, 1991, for a review). Different terms have been used to describe these processes, but by far the most common terms are recollection and familiarity. Recollection is thought to be an intentional and deliberate process that allows the rememberer to "relive" prior experience and retrieve contextual detail (e.g., time or place) along with the to-be-remembered event. In contrast, familiarity-based recognition is usually described as an automatic, unconscious process of memory that does not involve retrieval of contextual detail. In the original dual-process formulations, perceptual processing was considered the most important underpinning of familiarity (e.g., perceptual codes, Atkinson \& Wescourt, 1975; intraitem perceptual integration, Mandler, 1980; perceptual fluency, Jacoby \& Dallas, 1981, and Johnson, Dark, \& Jacoby, 1985). For example, Mandler (1980) has

Portions of this research were presented at the annual meeting of the Canadian Society for Brain, Behaviour and Cognitive Science, June 18-20, 1998, Ottawa, Ontario, Canada and at the 39th Annual Meeting of the Psychonomic Society, Dallas, November 1998. Preparation of this article was supported by Natural Sciences and Research Council of Canada research grants to each author. We thank Christine Werk and Michelle Arnold for research assistance. We also thank John Kihlstrom, Jeff Bowers, and Peter Graf for their comments on an earlier draft of this article. Correspondence concerning this article should be addressed to P. A. Higham, Department of Psychology, University of Southhampton, Highfield, Southampton, SO17 IBJ England (e-mail: higham@soton.ac.uk). argued that item repetition increases integration of its perceptual features, thus incrementally increasing familiarity. Such a description explains why frequently presented target items receive fast, accurate hits, whereas frequently presented distractors lead to slower, inaccurate judgments (Atkinson \& Juola, 1974). Similarly, current fluency in perceiving an item under perceptually degraded conditions has been proposed as one potential, measurable underpinning of the feeling of familiarity (e.g., Jacoby \& Dallas, 1981; Johnson et al., 1985). Dual-process models have recently incorporated conceptual as well as perceptual familiarity mechanisms (e.g., Jacoby, 1991; Whittlesea, 1993; Whittlesea \& Williams, 1998, 2000).

Investigations directed at determining the causes of feelings of familiarity or, more generally, the role of processing fluency in recognition have become a literature in their own right, whether these investigations occurred with normals (Jacoby \& Brooks, 1984; Jacoby, Kelley, \& Dywan, 1989; Rajaram, 1993; Whittlesea, 1993; Whittlesea, Jacoby, \& Girard, 1990; Whittlesea \& Williams, 1998,2000 ) or with special populations (e.g., Dorfman, Kihlstrom, Cork, \& Misiaszek, 1995; Yonelinas, Kroll, Dobbins, Lazzara, \& Knight, 1998). For example, Jacoby and colleagues have argued that the subjective experience of familiarity can arise from an attribution process. In particular, a feeling of familiarity can result when a person processes a stimulus fluently and attributes that fluency in processing to having encountered the stimulus before. Since previously encountered items are processed more fluently than novel items (e.g., perceptual priming; 
Jacoby \& Dallas, 1981), attributions of this sort are quite reasonable; fluently processed items are more likely to be old than are nonfluently processed items, so relying on fluency of processing to make recognition memory judgments will result in above-chance memory performance.

\section{Fluency, Prime Identification, and the Item Selection Artifact}

Despite the fact that factors such as perceptual priming can lead to fairly accurate fluency-based memory judgments, it is also clear that relying on fluency to make memory judgments can lead to errors. For example, if the fluency with which a stimulus is processed is high for reasons other than prior exposure, people might misattribute this fluency to prior exposure, resulting in an illusory feeling of familiarity (see, e.g., Jacoby \& Dallas, 1981; Jacoby et al., 1989; Jacoby \& Whitehouse, 1989; Whittlesea, 1993; Whittlesea et al., 1990; Whittlesea \& Williams, 1998, 2000). In this vein, Watkins and Gibson (1988, Experiment 2) showed participants a list of words followed by a recognition memory test. However, prior to the presentation of each target word for recognition, the same word was briefly presented as a prime for varying duration. They found that if participants identified the prime, they gave higher recognition ratings than if they misidentified the prime. They suggested that this result would be expected if memory judgments were based on processing fluency and prime identification indexed that fluency. However, rather than seeing these results as an example of illusory familiarity, Watkins and Gibson suggested that their correlation between prime identification and recognition was attributable to an item selection artifact. Since in their design, prime identification was a post hoc variable based on participants' responding, any correlation between prime identification and recognition could potentially be due to correlations between particular item properties, recognition memory judgments, and identification likelihoods. For example, words of high lexical frequency may be more likely to be identified and also more likely to be rated old in a recognition memory test than are low-frequency words. If this were the case, a correlation between prime identification and recognition might be misinterpreted as reflecting a causal link between an item's perceptual fluency and its level of familiarity. However, the relationship between identification and recognition in this case is not causal. Rather, it is due to the fact that the two sets of items in the analysis differed in terms of lexical frequency, and lexical frequency is correlated with both identification and recognition responses. We will refer to this explanation of the observed relationship between prime identification and recognition as the item selection explanation.

Watkins and Gibson (1988) argued that to eliminate the item selection explanation, it was necessary to demonstrate that their experimental manipulation of prime display duration (used to manipulate prime identification) exerted a significant effect on recognition judgments independent of whether or not particular primes were iden- tified. Since particular items were counterbalanced through the different prime duration conditions, any effect of duration, collapsed across prime identification, could not have been due to the selection of particular items. This effect did not approach significance in Watkins and Gibson's research. Thus, although Watkins and Gibson found that prime identification was associated with higher recognition ratings, there was no evidence to bring into question the item selection explanation of their results.

However, we believe some caution should be exerted before accepting the item selection explanation of Watkins and Gibson's (1988) results. Had Watkins and Gibson found even a small, but statistically significant, effect of prime display duration collapsed across prime identification, item selection would have to have been abandoned as the complete explanation. Furthermore, there is reason to suspect that the experimental effect of prime display duration would have been weak anyway, even if perceptual fluency actually did exert direct control over recognition in their experiment. In Watkins and Gibson's Experiment 2, 43\% of the items in the shortest display duration condition were correctly identified (fluent), and $34 \%$ were misidentified (nonfluent) in the longest display duration condition. Inclusion of these trials weakened the correlation between prime identification and prime display duration. In fact, we estimated the correlation between prime identification and prime display duration for these data to be merely .22 . This correlation means that, on average across participants, the independent variable of prime display duration was a weak manipulation of prime identification. Thus, contrary to Watkins and Gibson's claim, failing to find an effect of prime display duration in their Experiment 2 does not provide compelling evidence against a direct effect of perceptual fluency on recognition. Had Watkins and Gibson used a more extreme manipulation of prime display duration, so that fewer primes would be identified in the shortest duration condition and fewer primes would be misidentified in the longest duration condition (enhancing the correlation between identification and duration), an experimental effect of duration might have been obtained. In short, the null effect of prime display duration in Watkins and Gibson's Experiment 2 is a weak basis for accepting the item selection explanation.

\section{Processing Fluency and Illusory Familiarity}

Subsequent research has provided evidence for illusory familiarity's arising from test-time manipulations of processing fluency that is not subject to the item selection explanation (e.g., Jacoby \& Whitehouse, 1989; Lindsay \& Kelley, 1996; Whittlesea, 1993; Whittlesea et al., 1990; Whittlesea \& Williams, 1998, 2000). For example, in Jacoby and Whitehouse's experiments (see also Bernstein \& Welch, 1991; Joordens \& Merikle, 1992), participants also were shown a list of words and later were given a recognition memory test. As with Watkins and Gibson (1988), prior to the presentation of each target word for recognition, a prime word was presented for 
Table 1

Mean Prime Identification Likelihoods

(With Standard Errors) in Experiments 1, 2, and 3

as a Function of Prior Processing and Prime Duration

\begin{tabular}{|c|c|c|c|c|c|c|c|c|c|}
\hline \multirow[b]{3}{*}{ Experiment } & \multirow{3}{*}{$\begin{array}{l}\text { Prime Durations } \\
\text { (msec) }\end{array}$} & \multicolumn{8}{|c|}{ Experimental Condition } \\
\hline & & \multicolumn{2}{|c|}{ Short-Old } & \multicolumn{2}{|c|}{ Long-Old } & \multicolumn{2}{|c|}{ Short-New } & \multicolumn{2}{|c|}{ Long-New } \\
\hline & & $M$ & $S E$ & $M$ & $S E$ & $M$ & $S E$ & $M$ & $S E$ \\
\hline 1 & 20 and 50 & .32 & .02 & .87 & .03 & .23 & .02 & .78 & .03 \\
\hline 2 & 15 and 250 & .07 & .01 & .97 & .01 & .05 & .01 & .97 & .01 \\
\hline \multirow[t]{2}{*}{3} & 16.67 and 50 & .17 & .02 & .93 & .02 & .10 & .02 & .89 & .02 \\
\hline & 16.67 and 250 & .11 & .03 & .98 & .01 & .05 & .01 & .98 & .01 \\
\hline
\end{tabular}

varying duration. However, in contrast to Watkins and Gibson, rather than always matching the prime with the target (e.g., table primed with table; matched trials), some of the prime-target pairs were mismatched (e.g., table primed with sugar; mismatched trials). Jacoby and Whitehouse showed that for short prime duration trials, where participants could not identify the prime word, more old responses were made to prime-target matches than to prime-target mismatches. The opposite pattern was obtained for long prime duration trials where participants were able to identify the prime; fewer old responses were made if the prime and target matched than if they did not. In contrast with Watkins and Gibson, Jacoby and Whitehouse did not ask their participants to identify the prime in the short-duration condition; in fact, the participants were not even told that a prime was presented. However, Joordens and Merikle have since found that this instruction is not crucial to replicating Jacoby and Whitehouse's pattern of results. In Joordens and Merikle's Experiment 3, participants were told about the presence of the prime word in all the conditions, and the short-duration condition (where few or no primes were identified) still produced a qualitatively different pattern of recognition memory results than did the long-duration condition (where most or all primes were identified).

Jacoby and Whitehouse's (1989) explanation of this pattern was that, on matched trials, the target was processed more fluently than on mismatched trials. Thus, on matched trials where participants did not identify the prime, the added fluency from a prime-target match was misattributed to prior presentation (i.e., earlier membership in the study list). This misattribution resulted in a feeling of familiarity and more judgments of old on matched trials than on mismatched trials. Conversely, on matched trials where participants identified the prime, the added fluency from a prime-target match was attributed to the presence of the prime, not presentation during the training phase. Participants actually went too far in their attribution of fluency to prime presentation in the condition in which participants identified the prime; targets on matched trials were less likely to be rated old than were targets on mismatched trials. This interaction between prime type and prime identification on recogni- tion memory has since been replicated in other laboratories (e.g., Bernstein \& Welch, 1991; Joordens \& Merikle, 1992).

\section{Overview of the Experiments}

Unlike Watkins and Gibson (1988), Jacoby and Whitehouse (1989) investigated illusory familiarity by focusing on the match-mismatch comparison. However, since they varied prime display duration within a condition in which the prime and the target were always matched, they have what appears to be a partial methodological replication of Watkins and Gibson's experiment. Despite the methodological similarity, however, the results from the two laboratories are contradictory; although they did not specifically test for it, in both of Jacoby and Whitehouse's experiments, identified primes on matched trials were associated with a reduced, rather than an increased, likelihood of rating the target old, relative to unidentified primes. For example, the false alarm rates were .24 (identified) versus .36 (unidentified) for Experiment 1 and .21 (identified) versus .26 (unidentified) for Experiment 2 (Jacoby \& Whitehouse, 1989, Table 1).

In sum, there are two reasons to be interested in Watkins and Gibson's (1988) experiment using matched trials. First, the item selection explanation of their results is questionable. Second, the direction of the relationship between prime identification and recognition is equivocal. Accordingly, in the experiments reported in this paper, we more closely investigated the memory illusion described by Watkins and Gibson, to discover whether it is wholly attributable to item selection. If it is not, it is important for fluency attribution theories to determine under what conditions prime identification is associated with increased versus decreased old responses in recognition. Experiment 1 was conducted in an attempt to replicate Watkins and Gibson, but with a greater correlation between prime identification and prime duration. In Experiment 2, we varied the difference between the long and the short prime display durations. This change allowed us to explore one potential cause of the different matched trial results obtained by Jacoby and Whitehouse (1989) and Watkins and Gibson. In Experiment 3, we included both manipulations within a single experiment and 
adjusted the display procedure to produce two discrete prime display durations, rather than the uniform variations used in Experiments 1 and 2.

Our research differs from other research in this area in that we are making no strong claims regarding unconscious processing. Our primary interest was in the effect of prime identification on recognition decisions, not prime awareness per se. Although some may argue that the ability to identify the prime and conscious awareness of the prime are essentially synonymous, there are others who have argued that this is not necessarily the case. For example, Bernstein and Welch (1991) demonstrated that even with prime display durations that matched Jacoby and Whitehouse's (1989) shortest duration condition ( $16 \mathrm{msec}$ ), participants could judge well above chance whether the prime and the target matched. They suggested that such results refute the claim that participants were unaware of the prime. Such debates are peripheral to the main aims of this paper; suffice it to say that, because prime identification is the variable that is likely to moderate the attribution process, it is this variable that we will consider closely. Since prime identification is a function of participants' performance, it was not manipulated directly but, rather, by varying the display duration of the prime. This approach follows that of Watkins and Gibson (1988) and Jacoby and Whitehouse.

\section{EXPERIMENT 1}

Experiment 1 followed the general procedures of Watkins and Gibson's (1988) Experiment 2. Thus, the participants first studied a long list of words and later were administered a recognition memory test in which each test item was preceded by a matching prime displayed for a variable duration. The participants were asked to attempt to identify the prime (guessing, if necessary) and then to make a recognition response to the test item presented in the clear. As in Watkins and Gibson, we measured the accuracy of the identification attempt (correct/incorrect) and the recognition response to the target (old/new). However, our procedure differed from theirs in two ways. First, for the manipulation of prime display duration, we reduced the number of levels from three to two and dropped the complex titration method Watkins and Gibson had used to adjust these durations on line for each participant. Second, the participants were required to give speeded recognition responses to the target items. This requirement was meant to persuade the participants to use a nonanalytic basis of responding (Jacoby \& Brooks, 1984) in the hope that it would increase the effect of prime identification on recognition. If Watkins and Gibson's results are to be replicated, we should find that targets following identified primes are more likely to be rated old than are targets following misidentified primes. Also, if an item selection interpretation of this effect is to be eliminated, it is also necessary to find a significant effect of prime display duration collapsed across prime identification.

\section{Method}

\section{Participants}

The participants were 27 University of Northern British Columbia introductory psychology students with normal or corrected-tonormal vision, who participated in return for course credit. They were tested in groups of 1-3 at individual workstations. Nine participants were replaced because they failed to provide data in all the relevant cells of the design (e.g., they may have failed to identify any items in the short prime duration condition or have identified all the items in the long prime duration condition).

\section{Apparatus}

All the displays were generated by Pentium computers using the default $25 \times 80$, white-on-black text mode of MS-DOS with $640 \times$ 400 displays. The vertical refresh rate was $70 \mathrm{~Hz}$. All the training and test items were displayed in lowercase, centered vertically and horizontally on the screen.

\section{Design and Materials}

Study phase. One hundred and forty-eight five-letter English words of medium lexical frequency (mean frequency of 30 occurrences per million, with a standard deviation of 52) were used as stimuli. The pool was divided into two lists of 74 items each that were balanced in terms of lexical frequency. Each participant was shown words from only one of the lists during the training phase. Words from the exposed list acted as old words on the recognition test, whereas words from the unexposed list acted as new words. Assignment of lists to the old and new conditions was counterbalanced across participants.

Test phase. All 148 words from both training lists were presented in the test phase of the experiment. Each test trial consisted of (1) a fixation stimulus $\left({ }^{*}\right)$ presented for $1,000 \mathrm{msec},(2)$ presentation of the prime for either a short or a long duration, (3) presentation of a mask ( $\& \& \& \& \&)$ that remained in view until the space bar was depressed, (4) a 500-msec blank screen, and (5) presentation of the target (which always matched the prime) until a recognition response was made. Half the words on the test list were presented for a short duration (mean $=20 \mathrm{msec}$ ), whereas the other half were presented for a long duration (mean $=50 \mathrm{msec}$ ), and this factor was crossed with prior presentation (old vs. new). This experiment and the next used $70-\mathrm{Hz}$ monitors; thus, each prime was displayed for the mean duration of its experimental condition plus or minus $14.3 \mathrm{msec}$. Prime duration for each experimental condition, then, was not fixed but was distributed uniformly around a particular mean display duration. Consequently, the participants would experience a uniform range of prime display durations from potentially no display at all to over $64 \mathrm{msec}$. This design yielded four experimental conditions; old-short, old-long, new-short, and new-long. Assignment of words to the long and short-duration conditions was also counterbalanced across participants.

\section{Procedure}

Study phase. The participants were instructed to try to memorize the word list that would be presented to them on the computer screen by silently reading each word. To reinforce the instructions, a message to this effect appeared on the computer screen for the participants to read after they had received the instructions verbally.

After the participants indicated that they understood the instructions, they pressed the space bar, and each word from the 74-word training list was presented once to each participant, one at a time, for $2 \mathrm{sec}$ each in a random order. When all 74 words had been presented, a message was displayed that indicated that the training phase had ended and that they should wait for instructions.

Test phase. The participants were informed that the test phase consisted of a series of trials. Each trial began with the presentation of a fixation stimulus $\left(^{*}\right)$ that indicated where the rest of the events 
Table 2

Mean Likelihoods (With Standard Errors) of Responding

Old to Targets in Experiment 1 as a Function of Prior

Presentation, Prime Identification, and Prime Duration

\begin{tabular}{|c|c|c|c|c|c|c|c|c|}
\hline \multirow[b]{3}{*}{ Prime Status } & \multicolumn{8}{|c|}{ Experimental Condition } \\
\hline & \multicolumn{2}{|c|}{ Short-Old } & \multicolumn{2}{|c|}{ Long-Old } & \multicolumn{2}{|c|}{ Short-New } & \multicolumn{2}{|c|}{ Long-New } \\
\hline & $M$ & $S E$ & $M$ & $S E$ & $M$ & $S E$ & $M$ & $S E$ \\
\hline Identified $\mathrm{p}$ & .77 & .03 & .76 & .03 & .46 & .05 & .42 & .04 \\
\hline Misidentified primes & .66 & .03 & .70 & .06 & .31 & .04 & .41 & .05 \\
\hline
\end{tabular}

in the trial would occur, and the participants were instructed to look at it while it was in view. Following the fixation stimulus, a word was briefly presented and then masked with ampersands (\&\&\&\&\&). These ampersands remained in view, along with a prompt instructing the participants to identify the word by typing in a response on the keyboard, guessing if necessary. The program used to conduct the experiment did not allow the participants to advance to the next stage until some attempt had been made to identify the prime. This requirement that the participants provide some response to every prime, including those they could not identify, was, in part, an attempt to control the time from the prime offset to the onset of the presentation of the target for recognition. Clearly, this approach will at best only roughly equate this period between identified and misidentified prime trials, but it represents a compromise between the self-paced procedure of Watkins and Gibson (1988) and the fixed period found in Jacoby and Whitehouse (1989).

After attempting to identify the prime, the participants were instructed (on the screen) to press the space bar to reveal the test item. The participants were instructed to press the key labeled "Y" (actually the " 1 " key on the keyboard), to indicate that the item was in the training list, or the key labeled " $N$ " (actually the " 0 " key on the keyboard) to indicate that it was not. They were informed that their reaction times (RTs) were being measured and that they should make the recognition response as quickly as possible without sacrificing accuracy. There was a 500-msec blank screen delay after pressing the space bar before the test item appeared, to ensure that the participants had enough time to ready themselves for the speeded recogtition response. Although RTs were not analyzed, trials on which the participants took longer than $2 \mathrm{sec}$ to respond and trials on which the participants pressed a wrong key after target presentation were treated as error trials and were eliminated from the analysis.

The participants were informed that these trials were errors with a beep from the computer and a flashing message indicating the nature of the mistake. On average, $96 \%$ of the possible 148 items each participant received contributed to the analyses.

\section{Results and Discussion}

Our primary interest in this research was in the effect of prime identification on subsequent recognition memory judgments, but the likelihood of prime identification was experimentally manipulated by varying prime display duration. Therefore, for the recognition data in this experiment, we will report both the results of an analysis that included prime identification as a post hoc variable and the results of an analysis that included only the experimental variables of prime display duration and prior presentation. The latter analysis allowed us to test for an effect of prime display duration collapsed across prime identification. As was outlined in the introduction, a significant effect of prime display duration collapsed across prime identification would allow us to eliminate the possibility that all of the prime identification effect on recognition was due to item selection. However, prior to reporting the results of these two analyses, we will first report the analysis of the identification likelihoods. An alpha level of .05 was adopted for all the statistical comparisons reported in this paper.

\section{Identification Performance}

The mean likelihoods of identifying primes in Experiment 1 , as a function of prior presentation and duration, are shown in Table 1. For each participant, we calculated the correlation between prime display duration and prime identification. This average correlation was .56, notably greater than the value of .22 we estimated from Watkins and Gibson's (1988) data. Thus, we succeeded in establishing a strong correlation between these variables. A 2 (prior presentation: old/new) $\times 2$ (duration: short/ long) within-subjects analysis of variance (ANOVA) on the identification data revealed main effects of prior presentation $\left[F(1,26)=60.85, M S_{\mathrm{e}}=0.003\right]$ and duration $\left[F(1,26)=918.54, M S_{\mathrm{e}}=0.009\right]$. Old items were more likely to be identified (.59) than were new items (.51) (perceptual priming; Jacoby \& Dallas, 1981), and primes presented for a long duration were more likely to be identified $(.82)$ than were primes presented for a short duration (.28). The interaction was not significant $(F<1)$.

\section{Effect of Prime Identification on Recognition Judgments}

Mean recognition likelihoods for targets, as a function of prime identification success, prime duration, and prior presentation, are shown in Table 2. A 2 (prior presentation: old $/$ new) $\times 2$ (duration: short/long) $\times 2$ (prime identification: yes/no) within-subjects ANOVA revealed main effects of prior presentation $[F(1,26)=88.74$, $\left.M S_{\mathrm{e}}=0.06\right]$ and identification $\left[F(1,26)=6.46, M S_{\mathrm{e}}=\right.$ $0.06]$. Old items were more likely to be rated old (.72) than were new items (.40), and targets following identified primes were more likely to be rated old (.60) than were targets following misidentified primes (.52). In addition, the ANOVA revealed a duration $X$ prime identification interaction $\left[F(1,26)=6.64, M S_{\mathrm{e}}=0.02\right]$, indicating that the effect of prime identification was larger for primes displayed for a short duration (.11) than for primes displayed for a long duration (.04). This interaction was unanticipated but will be discussed in greater 
detail in the General Discussion section. There was no residual effect of display duration once prime identification was controlled $(F<1)$. No other main effect or interaction was significant.

\section{Effect of Prime Duration on Recognition Judgments}

A 2 (prior presentation: old $/$ new) $\times 2$ (duration: short/ long) within-subjects ANOVA revealed a main effect of prior presentation $\left[F(1,26)=105.08, M S_{\mathrm{e}}=0.031\right]$. Old items were more likely to be rated old (.72) than were new items (.37). In addition, targets following primes displayed for a long duration were significantly more likely to be rated old (.58) than were targets following primes displayed for a short duration $\left[.52 ; F(1,26)=6.10, M S_{\mathrm{e}}=\right.$ $0.013]$. The interaction was not significant $(F<1)$. Overall, the results of this experiment replicate the results of Watkins and Gibson (1988), with one important difference. First, we obtained a perceptual priming effect (Jacoby \& Dallas, 1981); old items were identified better than new items under perceptually degraded conditions. Second, the analyses on the recognition data revealed that identifying the prime word significantly increased the likelihood of an old response to the matched target. However, unlike Watkins and Gibson, there was a significant effect of prime display duration, independent of prime identification. As a result, the item selection explanation can no longer be considered a complete account of the effect of prime identification on recognition. Contrary to Watkins and Gibson's conclusion, illusory familiarity can occur as a direct result of prime identification with a matched trials procedure, at least under the circumstances of our experiment.

\section{EXPERIMENT 2}

Experiment 1 established that the effect of prime identification on recognition could not have been due wholly to an item selection effect. Recall, however, that this effect is the reverse of that obtained with Jacoby and Whitehouse's (1989) matched trials: In Jacoby and Whitehouse, increased prime identification was associated with a reduced tendency to say old, whereas Experiment 1 showed an increased tendency. One possible explanation for the difference in pattern is that the observation in Jacoby and Whitehouse was not reliable; they explored the effects of prime identification across matched and mismatched trials but did not test for the related effects within trial type. If we assume that their effect was reliable, there are any number of methodological differences between the experiments that could account for the contradictory results. For example, in our experiment, the prime display durations averaged 20 and $50 \mathrm{msec}$, whereas in Jacoby and Whitehouse, the comparable short and long prime display durations were 50 and $200 \mathrm{msec}$ (Experiment 1 ) and 16 and $600 \mathrm{msec}$ (Experiment 2). Another methodological difference was the presence of mismatched trials in
Jacoby and Whitehouse. Either possibility, inter alia, could have changed the response strategies of the participants, leading to the difference in the results. Consequently, in Experiment 2, we used prime display durations that more closely resembled those of Jacoby and Whitehouse, while retaining the exclusive matched trials design of our Experiment 1 . If the contradictory results were due to the difference in prime display duration and not, for example, to the presence of mismatched trials, we would expect Jacoby and Whitehouse's results, rather than those observed in Experiment 1.

\section{Method \\ Participants \\ Thirty-six undergraduate psychology students at the University of Northern British Columbia participated in return for course credit. The participants were tested in groups of $1-3$.}

\section{Apparatus \\ The apparatus was identical to that used in Experiment 1 .}

\section{Design and Materials}

The design and materials were the same as those in Experiment 1 , except that the mean prime display duration in the shortduration condition was reduced from 20 to $15 \mathrm{msec}$, and the display duration in the long-duration condition was increased from 50 to $250 \mathrm{msec}$.

\section{Procedure}

The procedure was the same as that in Experiment 1.

\section{Results and Discussion}

Because the duration manipulation was so extreme, a post hoc analysis of recognition responses to targets broken down by prime identification was not feasible, since there were too many empty cells (i.e., the majority of the participants were unable to identify any items in at least one of the short-duration conditions). Consequently, for the recognition data, it was only possible to statistically analyze the experimental effect of duration; prime identification and prime display duration were logically the same variable, as with Jacoby and Whitehouse (1989). Also, the fact that the effect of prime display duration in Experiment 1 was mediated entirely by prime identification suggests that it is not unreasonable to equate these variables. After eliminating error trials, on average, $95 \%$ of the possible 148 items each participant received contributed to the analyses.

\section{Identification Performance}

The mean likelihoods of identifying primes in Experiment 2 , as a function of prior presentation and duration, are shown in Table 1. As in Experiment 1, we calculated the correlation between prime display duration and prime identification for each participant. In this case, the average correlation was 92 , indicating that these variables were virtually equivalent. A 2 (prior presentation: old/new) $\times$ 2 (duration: short/long) within-subjects ANOVA revealed a main effect of duration $[F(1,35)=10,850.07$, 
Table 3

Mean Likelihoods (With Standard Errors) of Responding Old to Targets in Experiment 2 and Mean Recognition Rating on a Scale of 1 (Sure Not Old) to 4 (Sure Old) of Targets in Experiment 3 as a Function of Prior Presentation and Prime Duration

\begin{tabular}{|c|c|c|c|c|c|c|c|c|c|}
\hline \multirow[b]{3}{*}{ Experiment } & \multirow[b]{3}{*}{ Conditions } & \multicolumn{8}{|c|}{ Experimental Condition } \\
\hline & & \multicolumn{2}{|c|}{ Short-Old } & \multicolumn{2}{|c|}{ Long-Old } & \multicolumn{2}{|c|}{ Short-New } & \multicolumn{2}{|c|}{ Long-New } \\
\hline & & $M$ & $S E$ & $M$ & $S E$ & $M$ & $S E$ & $M$ & $S E$ \\
\hline 2 & 15 and $250 \mathrm{msec}$ & .72 & .02 & .71 & .02 & .40 & .02 & .33 & .03 \\
\hline \multirow[t]{4}{*}{3} & 16.67 and $50 \mathrm{msec}$ & 3.04 & .07 & 3.16 & .08 & 2.12 & .10 & 2.27 & .10 \\
\hline & & .68 & .03 & .75 & .03 & .30 & .03 & .40 & .04 \\
\hline & 16.67 and $250 \mathrm{msec}$ & 3.20 & .08 & 3.12 & .05 & 2.19 & .06 & 2.06 & .07 \\
\hline & & .74 & .03 & .73 & .03 & .35 & .04 & .30 & .04 \\
\hline
\end{tabular}

Note-For convenience, the mean likelihoods of responding old to targets (scale responses $>3$ ) in Experiment 3 are shown as the second line for each of the two conditions of Experiment 3 .

$M S_{\mathrm{e}}=0.003$ ]. Primes presented for a long duration were much more likely to be identified (.97) than were primes presented for a short duration (.06). Since the identification of items presented for a long duration was near ceiling (.97), the analysis to test for perceptual priming was conducted on short-duration items only; it revealed a significant effect of prior presentation $[F(1,35)=5.65$, $M S_{\mathrm{e}}=0.002$ ]. Thus, perceptual priming (Jacoby \& Dallas, 1981) was apparent in this experiment, just as in Experiment 1 .

\section{Effect of Prime Duration/Identification on Recognition Judgments}

Mean ratings for old and new items in the short and long-duration conditions of Experiment 2 are shown in Table 3. A 2 (prior presentation: old $/$ new) $\times 2$ (duration: short/long) within-subjects ANOVA revealed main effects of prior presentation $\left[F(1,35)=172.32, M S_{\mathrm{e}}=0.03\right]$ and duration $\left[F(1,35)=4.91, M S_{\mathrm{e}}=0.01\right]$. Old items were more likely to be rated old (.71) than were new items (.37), and targets following primes displayed for a long duration were significantly less likely to be rated old (.52) than were targets following primes presented for a short duration (.56). The interaction was also significant; the effect of duration was greater for new items (.07) than for old items $\left[.01 ; F(1,35)=5.07, M S_{\mathrm{e}}=0.01\right]$. The principle result of this experiment was that by changing only the prime display durations to resemble more closely those of Jacoby and Whitehouse (1989), the effect of prime identification on recognition established in Experiment 1 was reversed.

\section{EXPERIMENT 3}

One concern of the previous experiments is that the reported durations of the prime displays were averages of the actual values, with a uniform distribution of $\pm 14.3 \mathrm{msec}$. Thus, for example, in Experiment 1, where the two levels of prime display duration differed by only $30 \mathrm{msec}$, the participants may have been unable to isolate discrete prime display duration levels, potentially compromising their ability to monitor correctly the source of their identification performance. This small $30-\mathrm{msec}$ difference, plus the uniformity of distributions, would have meant that the longest display in the short condition was essentially equivalent to the shortest display in the long condition. Thus, the participants in Experiment 1 may have had difficulty determining whether variability in prime identification performance was due to prior presentation or to the manipulated display duration of the prime. This potential confusion may have contributed to misattributions to prior presentation, resulting in the illusion of familiarity in Experiment 1. The large difference between the two prime display durations in Experiment 2 would render this confusion less likely, which provides a potential account of the different pattern of results found in that experiment.

For this reason, the next experiment attempted to replicate the results of both Experiments 1 and 2, but with fully discrete prime display durations. To do so, the prime displays were synchronized with the raster scan of the video monitors. Sixty-hertz video monitors were used in this experiment; so, to be synchronized with the raster scan of the monitors, prime display durations had to be some multiple of $1 / 60 \mathrm{sec}$. For the replication of Experiment 1 , prime display durations of $1 / 60$ and $3 / 60 \mathrm{sec}$ (16.67 and $50 \mathrm{msec}$ ) were used as the short and long display durations, respectively. For the replication of Experiment 2 , the durations used were $1 / 60$ and $15 / 60 \mathrm{sec}$ ( 16.67 and $250 \mathrm{msec}$ ). Thus, the only difference between the two replication conditions was the length of the long prime display duration, $50 \mathrm{msec}$ for one and $250 \mathrm{msec}$ for the other. Accordingly, for convenience, we will refer to them as the 50 - and the $250-\mathrm{msec}$ duration groups, respectively.

\section{Method}

\section{Participants}

Forty undergraduate psychology and neuroscience students from the University of Lethbridge served as participants. Twenty stu- 
dents, 5 in each of the four conditions necessary to counterbalance the materials through the two experimental factors of prior exposure and prime duration, participated in the replication of Experiment 1 (the 50-msec group), and the remaining 20 , again equally assigned to the four counterbalancing conditions, participated in the replication of Experiment 2 (the 250 -msec group). The participants were tested in groups of 1-4 at individual workstations.

\section{Apparatus \\ To achieve synchronization with the raster scan, Apple IIGS computers and monitors were used. These monitors have vertical refresh rates of $60 \mathrm{~Hz}$. All the items were displayed in lowercase, using the default $40 \times 24$, white-on-black text mode. \\ Design and Materials \\ The design and materials were similar to those in the previous experiments. The principal difference was that the prime displays were synchronized to the $60-\mathrm{Hz}$ raster scan of the video monitors by detecting the vertical blanking interval (or VBLINT) of the video monitors and by updating the video memory and, hence, the display only during this interval. Two further differences were that only 144 of the 148 five-letter words were used, and a five-letter word not from the original list was used as the first item in both the study and the test phases to demonstrate the procedure to the par- ticipants. Finally, all 144 items were systematically rotated through the four conditions produced by the combination of the two levels of prior presentation with the two levels of prime display duration in each of the two groups.}

\section{Procedure}

The procedure was the same as that in the previous experiments, except that the requirement for a speeded recognition judgment was dropped. Instead, immediately following the response to the prime, the target was presented in the center of the display, and a 4-point scale appeared at the top of the display, along with a prompt for the recognition judgment at the bottom. The participants selected a number from 1 to 4 as their recognition judgment, where 1 indicated sure not old, 2 indicated guess not old, 3 indicated guess old, and 4 indicated a judgment of sure old.

\section{Results and Discussion}

The results were analyzed similarly to those of Experiment 2. Because some of the participants in both groups failed to identify any of the short-duration primes (and many failed to misidentify any of the very long$250 \mathrm{msec}$-primes), it was not possible to analyze the post hoc effect of identification separately from duration, as was done for Experiment 1.

\section{Identification Performance}

The mean likelihoods of identifying primes in Experiment 3 , as a function of prior presentation and duration for each group, are shown in Table 1. As with Experiments 1 and 2, we calculated the correlation between prime display duration and prime identification for each participant. The mean correlation for the replication of Experiment 1 (i.e., the 50-msec group of Experiment 3) was .58 , almost identical to the value obtained for Experiment 1 and, again, much larger than the value of .22 that we estimated for Watkins and Gibson's (1988) data. For the replication of Experiment 2 (the 250-msec group of
Experiment 3), the mean correlation of .65 was significantly greater than that for the replication of Experiment $1\left[F(1,38)=15.01, M S_{\mathrm{e}}=0.003\right]$, but not as large as that obtained in Experiment 2 . Thus, our manipulations of prime display duration in this experiment were successful in producing a tighter link between duration and identification than in Watkins and Gibson's experiments.

A 2 (group: $50 / 250 \mathrm{msec}$ ) $\times 2$ (prior presentation: old $/$ new) $\times 2$ (duration: short/long) ANOVA on the identification data revealed significant main effects of prime display duration $\left[F(1,38)=3,555.95, M S_{\mathrm{e}}=0.008\right]$ and prior presentation $\left[F(1,38)=34.16, M S_{\mathrm{e}}=0.002\right]$. Old items were more likely to be identified (.55) than were new items (.51; perceptual priming; Jacoby \& Dallas, $1981)$ and primes presented for a long duration were more likely to be identified (.95) than were primes presented for a short duration (.11). Surprisingly, the identification rate averaged over the long and short display duration conditions of the 250 -msec group (.53) did not differ significantly from that of the 50 -msec group (.53; $F<1)$. However, group did interact significantly with duration $\left[F(1,38)=17.96, M S_{\mathrm{e}}=0.008\right]$, so that the effect of duration was larger for the 250-msec group than for the 50 -msec group. There was also a marginally-significant $(p=.06)$ interaction of group with prior presentation $\left[F(1,38)=3.67, M S_{\mathrm{e}}=0.002\right]$, so that the effect of prior presentation was marginally larger for the 50-msec group than for the 250-msec group. Prior presentation also interacted significantly with duration $\left[F(1,38)=7.51, M S_{\mathrm{e}}=\right.$ 0.002 ], with the effect of duration being slightly larger for new than for old items. The three-way interaction was not significant $(F<1)$.

\section{Effect of Prime Display Duration/Identification on Recognition Judgments}

Mean recognition ratings on the 4-point scale as a function of prior presentation and prime display duration for each of the two prime duration groups are shown in Table 3. A 2 (group: $50 / 250 \mathrm{msec}$ ) $\times 2$ (prior presentation: old $/$ new) $\times 2$ (duration: short/long) ANOVA on the these data revealed a significant main effect of prior presentation $\left[F(1,38)=209.52, M S_{\mathrm{e}}=0.18\right]$; old items received higher ratings of old (3.13) than did new items (2.16). There was no significant main effect of prime display duration $(F<1)$. Instead, there was a significant interaction of prime display duration with group $[F(1,38)=$ $\left.9.50, M S_{\mathrm{e}}=0.061\right]$. Prime display duration increased the recognition ratings for the 50 -msec group ( 2.58 vs. 2.72 for short and long, respectively), as in Experiment 1. In contrast, it decreased the ratings for the 250-msec group (2.69 vs. 2.59), as in Experiment 2. Analyzing the data for each group separately, the effect of prime duration was found to be significant within both duration groups [for the 50-msec group, $F(1,19)=4.59, M S_{\mathrm{e}}=0.081$, and for the 250-msec group, $\left.F(1,19)=5.31, M S_{\mathrm{e}}=0.041\right]$. Thus, the single change of the long-duration condition from 50 
to $250 \mathrm{msec}$ was sufficient to produce the reversal in the effect of prime display duration on recognition. No other effects were significant.

The significant effect of prime display duration within each of the two groups means that the effect of prime identification on recognition cannot wholly be due to an item selection artifact. Furthermore, the reversal of effect was found even when the prime displays were synchronized to the raster scan of the monitors, suggesting that the uniform distribution of prime display durations in Experiments 1 and 2 is not necessary to produce the effect. The results of Experiment 3 also demonstrate that the reversal observed between Experiments 1 and 2 can occur within an experiment with as simple a change as the lengthening of the long prime display duration from 50 to $250 \mathrm{msec}$.

\section{GENERAL DISCUSSION}

The results of the experiments support two general conclusions. First, all three experiments demonstrated that it is possible to produce a direct effect of prime identification on recognition, using matched primes and targets, that can not be attributed to an item selection artifact. Second, it is also possible, with only a minor change in procedure, to reverse the effect of prime identification on recognition, from one that increases the bias to respond old, to one that reduces it. This latter result suggests that how participants respond to variations in prime identification depends on the context in which these variations occur, a point we will return to below.

Having eliminated item selection as the sole explanation for the effect of prime identification on recognition, it may be fruitful to explore some alternate mechanisms. Our experiments in many ways resemble a repetition priming experiment, except that our participants were attempting to identify the prime. There is a possibility that correctly identifying the prime may have systematically affected the time from the prime offset to the onset of the presentation of the target for recognition. This possibility is worrisome from the repetition priming perspective, because such intervals may affect the influence of the prime on the target. However, because the effect of prime identification reversed between Experiments 1 and 2 (and between groups in Experiment 3), no simple, monotonic function relating prime-target intervals to target recognition can account for our results.

Most previous research on the heuristic basis of recognition memory has investigated misattributions that result from varying the fluency of processing of the current stimulus. On the one hand, there is a large research base suggesting that participants misattribute processing fluency caused by prior presentation to a variety of different sources: Anagrams seem easier (Jacoby \& Kelley, 1987), words appear to be displayed for longer periods (Witherspoon \& Allan, 1985), background noise seems less loud (Jacoby, Allan, Collins, \& Larwill, 1988), answers to general knowledge questions seem more accurate (Kelley \&
Lindsay, 1993), statements seem more true (Begg \& Armour, 1991), names seem more famous (Jacoby, Woloshyn, \& Kelley, 1989), and stimuli seem more pleasant (Zajonc, 1980). On the other hand, researchers have also demonstrated that current processing fluency is sometimes misattributed to the past, when it is actually caused by other sources, resulting in illusions of memory (e.g., Bernstein \& Welch, 1991; Higham \& Vokey, 2000; Jacoby \& Whitehouse, 1989; Joordens \& Merikle, 1992; Whittlesea, 1993; Whittlesea et al., 1990; Whittlesea \& Williams, 1998, 2000).

Attributions of current processing fluency theoretically could have produced the results of Experiment 2 and of the 250-msec group of Experiment 3; as Jacoby and Whitehouse (1989) argued, identification of the prime provides a plausible, available source for any target fluency, rendering misattributions to prior list membership less likely than for misidentified prime trials. However, it is 581 versed pattern of results in Experiment 1 and for the 50-msec group in Experiment 3. In those conditions, just as in Experiment 2, the identified prime is still the most plausible, available source of target fluency, so similar effects of prime identification should have been observed.

\section{The Discrepancy Attribution Hypothesis}

It is possible that attributions based on target fluency may explain both patterns of results if the theory is elaborated so as to take into account the differing test contexts of each experiment. For example, Whittlesea and Williams $(1998,2000)$ have argued that the subjective experience of familiarity is not the direct result of current fluent processing but, rather, depends on violations of the expected amount of fluency, given the current context. These authors note that stimuli are often processed extremely fluently, but no feeling of familiarity is experienced. For example, despite the extremely high fluency in processing associated with encountering one's spouse at home in the kitchen, no feeling of "pastness" results. The context of the kitchen sets up the expectation of high fluency in processing in this case, so no attribution to the past is made. Instead, they argue, (mis)attributions occur when there is discrepancy in the fluency of current processing, based on expectations. Thus, encountering one's spouse in a context where he or she is not usually encountered (e.g., in another city when travelling), the fluency in processing might be surprising, an attribution might be made to explain this fluency, and familiarity may result.

The discrepancy attribution hypothesis could potentially account for some subtleties in our data. For example, consider the prime display duration $\times$ identification interaction that was significant in Experiment 1. In this case, the effect of prime identification was larger for shortduration primes than for long-duration primes. It may be possible to explain this interaction by assuming that prime duration affected participants' confidence in their identification attempts; for short-duration trials, the fluency with which the target was processed following an 
identified prime was surprising because confidence that the identification attempt was correct was low. Conversely, the fluency of target processing following identified primes was not surprising for many long-duration trials because confidence in the identification attempt was higher. Thus, the discrepancy attribution hypothesis predicts that prime identification will result in more misattributions to prior exposure for short-duration trials than for long-duration trials.

Differential confidence may also explain the pattern of results that we obtained between Experiments 1 and 2 and the reversal pattern of Experiment 3. Identified primes in Experiment 1 and for the $50 \mathrm{msec}$ group in Experiment 3 were mostly primes displayed for $50 \mathrm{msec}$. Therefore, confidence was probably low in the accuracy of the identification attempts for these primes, and so subsequent processing fluency was not attributed to prime identification. Instead, the residual target fluency was misattributed to prior presentation, and a feeling of familiarity resulted. Conversely, participants probably had high confidence in the majority of prime identifications in Experiment 2 and by the 250-msec group in Experiment 3, since nearly all the identified primes were presented for $250 \mathrm{msec}$. Consequently, target processing fluency was attributed to prime identification, and no familiarity resulted. In fact, participants overshot and attributed too much fluency to prime identification for these trials.

Although the discrepancy attribution hypothesis apparently can account for the results of our experiments, we see a difficulty: It is not clear why the processing of targets following identified primes should be surprising at all, regardless of the prime display duration, given that prime identification provides such a reasonable source for that fluency. In other words, why are participants relying on their confidence in the accuracy of their identification attempt when, by the time they make a recognition response, they have already received feedback regarding their prime identification performance?

\section{The Identification Heuristic}

For these reasons, we do not believe that attributions based on target processing fluency, either as originally conceptualized or in the form of the discrepancy attribution hypothesis, can account for all of our results. Instead, we propose that the participants may also have based their recognition decisions directly on their success in identifying the prime once the target was presented. We will refer to this use of prime identification accuracy as the basis of recognition memory judgments as the identification heuristic. For example, in Experiment 1 and in the 50-msec group of Experiment 3, the participants may have reasoned (not necessarily consciously) that if their attempt to identify the prime was successful, the current target (which always matched the prime) is likely to be old because old items are more likely to be identified (as primes) than are new items. This strategy would result in an increased bias to respond old as a function of prime identification, the pattern observed in Experiment 1 and for the 50-msec group in Experiment 3. Note that this heuristic does not involve the attribution of target processing fluency per se but, rather, uses the target for feedback as to the accuracy of the prime identification attempt, and an attribution regarding the cause of success/ failure of prime identification is made; it is not target $f l u$ ency that is being misattributed to prior presentation but prime identification accuracy. This distinction is important because prime identification per se, by providing a source for fluency attributions, limits both misattributions of fluency to the past and the resulting memory illusion. This suppression of fluency-based misattributions to the past resulting from prime identification does not occur with attributions based on identification accuracy. Thus, the memory illusion observed in Experiment 1 and for the $50-\mathrm{msec}$ group in Experiment 3 produced by prime identification can be explained by misattributions of prime identification accuracy, but not by misattributions of target processing fluency (see Higham \& Vokey, 2000 , for further discussion of the phenomenology underlying this effect).

\section{Identification or Fluency: Which to Use?}

The results of our experiments suggest that attributions were sometimes based on prime identification (Experiment 1 and the 50-msec group in Experiment 3) and at other times on target fluency (Experiment 2 and the 250-msec group in Experiment 3). However, what determines the strategy that will be used? We suggest that one operative factor is the perceived reliability of prime identification as a predictor of prior presentation. In Experiment 1 and for the 50-msec group in Experiment 3, in addition to being very brief, the long- and short-duration conditions differed by only 30 (or 33.33 ) msec. From the participants' perspective, duration variations of this magnitude, in the context of such brief prime displays, may well affect identification performance in a way that is confusable with the way that prior presentation affects performance. In other words, from the participants' perspective, it is not unreasonable to attribute some variability in prime identification to prior exposure. Doing so would produce the memory illusion produced in Experiment 1 and with the 50-msec group in Experiment 3.

In Experiment 2 and for the 250-msec group of Experiment 3 , the difference in prime duration was increased, and variations in prime identification success were more readily attributable to the duration manipulation; that is, prior presentation, under these conditions, did not provide a reasonable source of variations in identification performance. As a result, we propose that the participants abandoned it as basis of recognition and searched for a new basis: target fluency. Switching from reliance on prime identification in Experiment 1 and by the 50-msec group of Experiment 3 to target fluency in Experiment 2 
and by the 250-msec group in Experiment 3 would have caused the reversal of the memory illusion observed between Experiments 1 and 2 and within Experiment 3.

\section{Awareness and the Experimental Manipulation}

Although we deliberately set out to make the manipulation of prime display duration more obvious in Experiment 2 and with the 250-msec group in Experiment 3, we do not believe, as others have suggested (e.g., Whittlesea, 1993; Whittlesea et al., 1990), that it was awareness of the experimental manipulation per se that stopped the reliance on prime identification success. Rather, we suspect that the participants were assessing the plausibility of potential causes of their subjective experience and were making attributions accordingly. Because prior presentation provided such a reasonable source of their prime identification performance, misattributions of prime identification to prior presentation would probably still have occurred in Experiment 1 and with the 50-msec group in Experiment 3, even if we had told them whether the prime display duration was long or short on a trialby-trial basis. Conversely, variations in prime identification performance in Experiment 2 and for the 250-msec group in Experiment 3 could not plausibly have been produced by prior presentation, and so the participants switched to a recognition basis believed to be more reliable: target fluency. We have no data bearing directly on the extent to which simple awareness of the duration manipulation could have mediated the participants' misattributions, but Whittlesea and Williams (2000) have recently found that some manipulations of processing fluency cannot be discounted, despite knowledge both of the manipulation of fluency and of the trials on which the experimenter intended fluency to be high. Their findings support our claim that unawareness of the experimenter's manipulation is not a necessary prerequisite for misattributions to occur.

\section{REFERENCES}

AtKinson, R. C., \& Juola, J. F. (1974). Search and decision processes in recognition memory. In D. H. Krantz, R. C. Atkinson, R. D. Luce, \& P. Suppes (Eds.), Contemporary developments in mathematical psychology: Vol. 1. Learning, memory and thinking (pp. 243-293). San Francisco: Freeman.

Atkinson, R. C., \& Wescourt, K. T. (1975). Some remarks on a theory of memory. In P. M. A. Rabbitt \& S. Dornic (Eds.), Attention and performance V (pp. 485-498). New York: Academic Press.

BegG, I., \& ARMour, V. (1991). Repetition and the ring of truth: Biasing comments. Canadian Journal of Behavioural Science, 23, 195 213.

Bernstein, I., \& WELCh, K. (1991). Awareness, false recognition, and the Jacoby-Whitehouse effect. Journal of Experimental Psychology: General, 120, 324-328.

Dorfman, J., Kinlstrom, J. F., Cork, R. C., \& Misiaszek, J. (1995). Priming and recognition in ECT-induced amnesia. Psychonomic Bulletin \& Review, 2, 244-248.

Higham, P. A., \& VoKey, J. R. (2000). Illusory recollection. Manuscript submitted for publication.

JACOBY, L. (1991). A process dissociation framework: Separating automatic from intentional uses of memory. Journal of Memory \& Language, 30, 513-541.

Jacoby, L., Allan, L., Collins, J., \& Larwill, L. (1988). Memory influences subjective experience: Noise judgments. Journal of Experimental Psychology: Learning, Memory, \& Cognition, 14, 240247.

JACOBY, L., \& BroOKs, L. (1984). Nonanalytic cognition: Memory, perception and concept formation. In G. H. Bower (Ed.), The psychology of learning and motivation (Vol. 18, pp. 1-47). New York: Academic Press.

JACOBY, L., \& DALLAS, M. (1981). On the relationship between autobiographical memory and perceptual learning. Journal of Experimental Psychology: General, 110, 306-340.

$\mathrm{J}_{\mathrm{ACOBY}}$ L., \& KeLLEY, C. (1987). Unconscious influences of memory of a prior event. Personality \& Social Psychology Bulletin, 13, 314336.

JaCoBy, L., Kelley, C., \& Dywan, J. (1989). Memory attributions. In H. L. Roediger III \& F. I. M. Craik (Eds.), Varieties of memory and consciousness: Essays in honour of Endel Tulving (pp. 391-422). Hillsdale, NJ: Erlbaum.

JACOBY, L., \& WhITEHOUSE, K. (1989). An illusion of memory: False recognition influenced by unconscious perception. Journal of $E x-$ perimental Psychology: General, 118, 126-135.

JACOBY, L., WoloshyN, V., \& KeLleY, C. (1989). Becoming famous without being recognized: Unconscious influences of memory produced by dividing attention. Journal of Experimental Psychology: General, 118, 115-125.

Johnson, W., Dark, V., \& Jacoby, L. (1985). Perceptual fluency and recognition judgments. Journal of Experimental Psychology: Learning, Memory, \& Cognition, 11, 3-11.

JoORdens, S., \& MERIKLE, P. M. (1992). False recognition and perception without awareness. Memory \& Cognition, 20, 151-159.

Kelley, C., \& LindSAY, D. (1993). Remembering mistaken for knowing: Ease of retrieval as a basis for confidence in answers to general knowledge questions. Journal of Memory \& Language, 32, 1-24.

Lindsay, D., \& KelLEY, C. (1996). Creating illusions of familiarity in a cued recall remember/know paradigm. Journal of Memory \& Language, 35, 197-211.

MANDLER, G. (1980). Recognizing: The judgment of previous occurrence. Psychological Review, 87, 252-271.

MANDLER, G. (1991). Your face looks familiar but I can't remember your name: A review of dual process theory. In W. Hockley \& S. Lewandowsky (Eds.), Relating theory and data: Essays on human memory in honor of Bennet B. Murdock (pp. 207-225). Hillsdale, NJ: Erlbaum.

RaJARAM, S. (1993). Remembering and knowing: Two means of access to the personal past. Memory \& Cognition, 21, 89-102.

WATKINS, M., \& GiBSON, J. (1988). On the relation between perceptual priming and recognition memory. Journal of Experimental Psychology: Learning, Memory, \& Cognition, 14, 477-483.

WhitTLESEA, B. (1993). Illusions of familiarity. Journal of Experimental Psychology: Learning, Memory, \& Cognition, 19, 1235-1253.

WhitTLESEA, B., JACOBY, L., \& GiRARD, K. (1990). Illusions of immediate memory: Evidence of an attributional basis for feelings of familiarity and perceptual quality. Journal of Memory \& Language, 29, 716-732.

WhitTlesea, B., \& Williams, L. (1998). Why do strangers feel familiar, but friends don't? The unexpected basis of feelings of familiarity. Acta Psychologica, 98, 141-165.

WhitTLESEA, B., \& WiLliams, L. (2000). The source of feelings of familiarity: The discrepancy-attribution hypothesis. Journal of Experimental Psychology: Learning, Memory, \& Cognition, 26, 547-565.

Witherspoon, D., \& Allan, L. G. (1985). The effect of a prior presentation on temporal judgments in a perceptual identification task. Memory \& Cognition, 13, 101-111.

Yonelinas, A. P., Kroll, N. E. A., Dobbins, I., Lazzara, M., \& KNIGHT, R. T. (1998). Recollection and familiarity deficits in amnesia: Convergence of remember-know, process dissociation, and receiver operating characteristic data. Neurophysiology, 12, 323-339.

ZaJonc, R. (1980). Feeling and thinking: Preferences need no inferences. American Psychologist, 35, 151-175.

(Manuscript received September 8, 1998; revision accepted for publication July 8,1999 .) 